\title{
BRDF-CORRECTED VEGETATION INDICES CONFIRM SEASONAL PATTERN IN GREENING OF FRENCH GUIANA'S FORESTS
}

Emil A. Cherrington ${ }^{12} 3$, Grégoire Vincent ${ }^{1}$, Daniel Sabatier ${ }^{1}$, Nicolas Barbier ${ }^{1}$, Uta Berger ${ }^{3}$ and Raphael Pélissier ${ }^{1}$ 1: Institut de recherche pour le développement (IRD) / UMR AMAP, TA A-51/PS1, 34398 Montpellier cedex 05, France emil.cherrington@ird.fr

2: AgroParisTech, 648 Rue Jean-François Breton, 34093 Montpellier cedex 05, France

3: Institut für Waldwachstum und Forstliche Informatik, Technische Universität Dresden, D-01735, Tharandt, Germany

\begin{abstract}
Résumé
Parmi les outils de caractérisation de la dynamique forestière, la télédétection est particulièrement adaptée pour l'observation des vastes surfaces forestières de Guyane d'accès difficile. Dans le but de réévaluer les hypothèses énoncées dans des études antérieures sur la capacité des capteurs optiques embarqués sur les satellites à détecter la dynamique de la phénologie, nous avons compilé sur une période de 12 années divers indices de végétation corrigés des effets bi-directionnels de variation des angles d'acquisition (BRDF). Ces indices sont issus de 2 capteurs optiques: SPOT VEGETATION, et MODIS (MODerate resolution Imaging Spectroradiometer). Les données ont été analysées pour évaluer les tendances saisonnières à l'échelle de l'ensemble de la Guyane et également sur quatre sites répartis sur ce territoire. Les données révèlent que les forêts de Guyane présentent un patron de saisonnalité. Le pic annuel des divers indices au cours de la période de septembre à octobre est interprété comme le reflet d'un pic de production de feuilles pendant la saison sèche.
\end{abstract}

Mots-clés : phénologie, LAI, forêt tropicale, MODIS, SPOT VEGETATION, séries temporelles

\begin{abstract}
Remote sensing is a useful tool set for monitoring changes in forest ecosystems, particularly remote and otherwise inaccessible tracts of tropical forest. To revisit findings of earlier satellite-based studies of phenological variation in Amazonian forests, the current study focused on the variation of vegetation indices (VIs) of French Guiana. Specifically, 12 years of $\mathrm{VI}$ data which had been treated for bi-directional effects were extracted from the archives of 2 particular satellite sensors: the SPOT VEGETATION instrument, and MODIS (the MODerate resolution Imaging Spectroradiometer). At the scale of the entire territory of French Guiana, as well as at 4 sites across the territory, VI data displayed strong seasonal patterns, with the dry season months having significantly higher VI estimates than the wet season months. As VIs are considered proxies for photosynthetic activity, those seasonal variations would seem to indicate leaf-flushing across French Guiana's forests during the dry season months of September to October.
\end{abstract}

Keywords: phenology, LAI, tropical forest, MODIS, SPOT VEGETATION, time series

\section{Introduction}

Over 40 years of environmental remote sensing have resulted in the collection of massive quantities of data by an ever increasing number of earth observation satellites (Lillesand et al. 2007). Research on the world's forests has concurrently benefited from advances in remote sensing. Global-scale studies have exploited satellite data to examine trends in forest cover, deforestation, and reforestation, with such land cover change-related studies becoming more commonplace (e.g. Hansen et al. 2013). Nevertheless, one research niche that has not been well exploited is the use of remote sensing to understand the dynamic ecological processes of forests. In that vein, over the past decade or so, a number of studies have honed in on monitoring the phenology of forests, i.e. their rhythm of periodic growth, using transformed satellite data in the form of vegetation indices (e.g. Bradley et al. 2011, Gond et al. 2013, Myneni et al. 1997, Pennec et al. 2011, Viennois et al. 2013). Vegetation indices (VIs) represent ways to simplify somewhat complex spectral data into easily calculated and easily understood indicators of vegetation vigor (Tucker 1979).

Remote sensing of phenology has, however, not been without controversy. For instance, almost a decade ago, a pair of studies were published which drew particular conclusions about causes of phenology (Huete et al.
2006, Saleska et al. 2007). These studies analyzed satellite data over the Amazon and concluded that Amazonian rain forests 'green-up' during the dry season, in response to increased solar radiation. As acknowledged within the studies themselves, such interpretations went against conventional logic which suggested that tropical forests in general should not green-up in the dry season when moisture is lacking. A later study would make the case that the observed green-up was spuriously caused by a lack of standardization of the sun-sensor geometry - referred to as BRDF, the bi-directional reflectance distribution function (Morton et al. 2014). A complementary article explained that variations in viewing angle might cause vegetation to appear brighter or darker, thus spuriously increasing or decreasing estimates of 'greenness' (Soudani \& François 2014). Hence, BRDF corrections are applied to normalize illumination (Huete et al. 1999). The data used for the original Amazon analyses, derived from the MOderate Resolution Imaging Spectroradiometer (MODIS), had apparently not been treated for BRDF, leading later studies to point out that vegetation indices extracted from uncorrected MODIS data would not be suitable for use. As data not corrected for BRDF effects have been employed in a number of prior time-series analyses, the results of such studies are inevitably called into question (Morton et al. 2014, Nagol et al. 2015). 
Artefacts caused by BRDF are not insurmountable obstacles for data analysis, however, as BRDFcorrected data products do exist. NASA routinely generates surface reflectance products (e.g. MCD43B4) which are corrected for BRDF. These complement other available BRDF-corrected satellite-derived products such as the 'fraction of green vegetation cover' (FCOVER) product derived from the VEGETATION instrument (hereafter referred to as VGT), on SPOT-4 and SPOT-5 (Camacho et al. 2009, Baret et al. 2013). In addition, indices such as LAI, the Leaf Area Index, are "derived by explicitly accounting for changing viewing and illumination conditions" and are thus "free of sun-sensor geometry effects" such as BRDF (Bi et al. 2014). LAl products are available from MODIS, as well as from VGT.

Since BRDF affects reflectance estimates and consequently VIs, it might be that previously-reported trends - generated using uncorrected data - are invalid. However, as it is possible to utilize VIs which are either corrected for or insusceptible to BRDF, such trends can and should be re-examined. French Guiana represents an appropriate case study for such re-examination, based on an earlier study utilizing VIs not corrected for BRDF (Pennec et al. 2011). While the study focused primarily on the analysis of satellite data, it did show how seasonal patterns in both the Enhanced Vegetation Index $(E V I)$ and the Shortwave Water Stress Index (SWSI) seemed to confirm the phenology indicated in an earlier botanical study (Sabatier \& Puig 1986). (French Guiana's seasons are generally divided between a $\sim$ long rainy season spanning December to July, and a shorter dry season spanning July-November - Sabatier 1985.) Nevertheless, since the satellitebased study of French Guiana used data not corrected for BRDF, questions remain as to whether the previously noted seasonality in the VIs is indeed valid.

The principal objective of the present study is therefore to explore what BRDF-corrected VIs indicate regarding the seasonality (or possibly the lack thereof) of French Guiana's forests, taking advantage of the 'big data' of over a decade of BRDF-corrected observations from both MODIS and VGT. This study addresses the following research questions:

(i) At the scale of all of French Guiana, do BRDFcorrected VIs display seasonal variation? That is, are there significant variations in monthly VI estimates?

(ii) At finer spatial scales within French Guiana, do Vls also display seasonal variation?

\section{Materials \& Methods}

Due to their global coverage, data from both MODIS and VGT were selected as the principal inputs for this study. To reduce potential data volume and to follow in the steps of earlier studies, vegetation indices from the 2 sensors were selected (listed in Table 1). These included the EVI, the fraction of green vegetation cover (FCOVER), and the Leaf Area Index (LAI). While each index serves as a proxy for photosynthetic activity, the indices differ greatly in what they are supposed to estimate. EVI is designed to "quantify the 'green' vegetation signal across a global range of vegetation conditions while minimizing canopy influences associated with intimate mixing by non-vegetation related signals" (Huete et al. 1999). FCOVER is described as "the fraction of green vegetation covering a unit area of horizontal soil [...] correspond[ing] to the gap fraction in the nadir direction," and "a very good candidate for substitution of classical vegetation indices" (Camacho et al. 1999). Lastly, LAl "is defined as half the developed area of photosynthetically active elements of the vegetation per unit horizontal ground area" (Baret \& Weiss 2014).

Table 1. Vegetation indices used in this study

\begin{tabular}{|c|c|c|c|c|}
\hline No. & Index & Product & Source & Period \\
\hline 1 & $\mathrm{EVI}$ & $\begin{array}{l}\text { MCD43B4- } \\
\text { derived }\end{array}$ & \multirow{2}{*}{ MODIS } & \multirow{2}{*}{$\begin{array}{l}\text { July } \\
2002- \\
\text { present }\end{array}$} \\
\hline 2 & LAI & MCD15A2 & & \\
\hline 3 & FCOVER & V1 & \multirow{2}{*}{ VGT } & \multirow{2}{*}{$\begin{array}{l}\text { Dec. } \\
\text { 1998- } \\
\text { Apr. } \\
2014\end{array}$} \\
\hline 4 & LAI & V1 & & \\
\hline
\end{tabular}

MODIS and VGT have provided in excess of 15 years of data to date, via the presence of twin MODIS sensors on the Aqua and Terra platforms, and twin VGT instruments on the now-defunct SPOT-4 and SPOT-5 satellites (Lillesand et al. 2007). However, to ensure comparability between the MODIS- and VGT-derived data, only data corresponding to the temporal overlap between the sensors was used. That corresponded to the almost 12 year period spanning July 2002 (following the launch of MODIS Aqua) through March 2014 (just prior to SPOT-5's end of mission). The data represented acquisitions from approximately 4,292 days, but which were analyzed in terms of the 141 constituent months, facilitating the handling of a large volume of data. Also, the MCD43B4 data were resampled from $500 \mathrm{~m}$ spatial resolution to match the, 1 $\mathrm{km}$ resolution of the other datasets.

\subsection{Reflectance data}

While the VGT data was already readily available in the form of pre-processed indices (i.e. FCOVER, LAI), in the case of MODIS, the EVI data had to be derived from the raw reflectance data. Nadir BRDF-corrected reflectance estimates from MODIS (the MCD43B4 product, collection 5) for French Guiana (tile h12v08 in the MODIS reference system) were acquired for the period indicated. MCD43B4 is based on reflectance estimates from both MODIS Aqua and MODIS Terra, and the quality is considered better than products derived from only a single satellite. Data were filtered using the quality assessment-quality control (QA/QC) data from the corresponding MCD43B2 dataset, whose archive had also been acquired. Quality of the input data was assured by selection of only "best quality, full inversion" reflectance data (Schaaf et al. 2002).

Since the MCD43B4 data was available as 424 overlapping 16-day datasets (and not as monthly data), that data was 'compressed' into monthly data: (i) the 141-month archive, and (ii) a compressed 12-month archive representing mean monthly reflectances over a calendar year. For instance, in the latter case, mean September reflectance would refer to the reflectance 
averaged from September data for all the years analyzed (i.e. 2002-2013). To reduce noise in the latter dataset, the monthly means were extracted by taking the minimum reflectance for each 16 day period for all spectral bands, with the exception of the near infrared band, from which the maximum reflectance was extracted to remove noise, following an approach presented in an earlier study (Hansen et al. 2003). This was done because in most spectral bands, cloud cover and aerosols increase spectral reflectance, but in the near-infrared band, the effect is the opposite (Jensen, 2006).

\subsection{Vegetation indices}

EVI was extracted from the monthly MCD43B4 reflectance data using the blue, red, and near-infrared bands. MODIS LAI data were also extracted from the MCD15A2 product, an 8-day product also using observations from both MODIS instruments. For the MCD15A2 data, quality assessment flags were used to ensure the extraction of only the highest quality observations. To allow for comparison with the earlier French Guiana satellite-based phenology study, EVI data from the MOD13A2 product was also extracted, for the time-period considered (Pennec et al. 2011). This study examined $\mathrm{VI}$ variation across 5 forest types mapped via unsupervised classification. The MOD13A2 data included here would thus be equivalent to agglomerating the VI trends from those 5 types, and is thus in essence a re-creation of the data from Pennec et al. (2011). Data from all sources were originally acquired at the scale of the Guiana Shield and subsequently subset to French Guiana. Additional filtering to derive monthly data was unnecessary for the VGT-derived FCOVER and LAI data, as the data already represent 30 -day observations. To limit the analysis to forest, data from other vegetation types was masked out, using a forest mask derived from unsupervised classification of MCD43 reflectance data. The mask was similar to the approach used in the earlier study (Pennec et al. 2011).

Statistical analyses were done to determine (i) whether there were statistically significant differences between monthly $\mathrm{VI}$ estimates (using the Kruskal-Wallis multiple comparison test), and (ii) the extent to which the different VIs were correlated to each other (using the Pearson product-moment correlation coefficient). With the Kruskal-Wallis test, pair-wise comparisons of the mean monthly VI estimates were done to determine whether or not the differences between monthly values were significant (Pohlert 2014).

\subsection{Impact of observation scale}

It was noted that territorial-level variation in VI estimates might not necessarily apply to finer spatial scales. Data were therefore analyzed for 4 dispersed, smaller sites (Figure 1). These were: (i) the mangroves of the Marécages de Kaw in northeast French Guiana $\left(439 \mathrm{~km}^{2}\right)$, (ii) the mixed forest in Montagne Plomb in north-central French Guiana $\left(122 \mathrm{~km}^{2}\right)$, (iii) the Parinaridominated forests near the Waki River in south-central French Guiana $\left(85 \mathrm{~km}^{2}\right)$, and (iv) the mixed low forest area near the Arawa mountains, also in south-central French Guiana $\left(23 \mathrm{~km}^{2}\right)$. Where the unsupervised classification indicates that French Guiana's forest cover is approximately $82,100 \mathrm{~km}^{2}$ (approx. 98\% forest cover), the 4 sites represent only $0.81 \%$ of the territory's total forest area. A data subset was extracted for each site, and the 4 data subsets were analyzed.

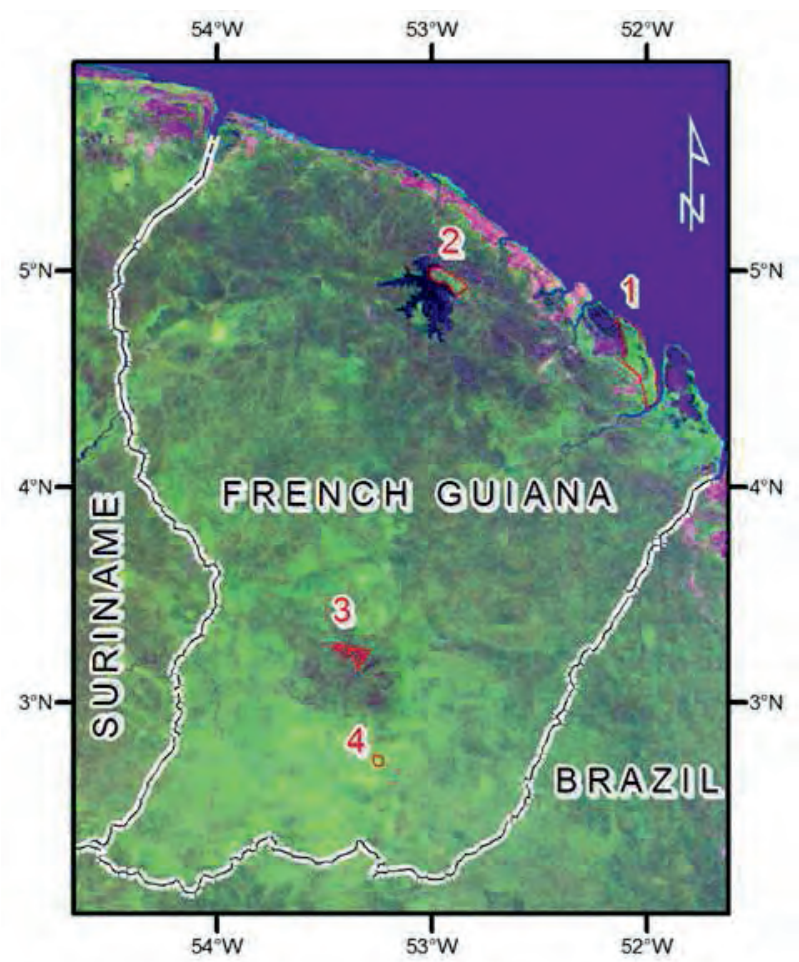

Figure 1: MCD43B4-derived September reflectance for French Guiana (12-year average), and location of 4 study sites (1: Kaw, 2: Mt. Plomb, 3: Waki, 4: Arawa).

\section{Results}

\subsection{VI variation at the scale of French Guiana}

Comparison of the mean monthly values for the different VIs - derived from $\sim 12$ years of data - show what appear to be distinct seasonal patterns (Figure 2). In general, the patterns appear more distinct for the 4 BRDF-corrected VIs shown, as compared to the single uncorrected VI shown, with the latter being essentially a reproduction from the data presented in an earlier study (Pennec et al. 2011). The 2 MODIS-derived products (EVI and LAI) indicate that the peak of 'greenness' I vegetation vigor is in September. By comparison, the VGT-derived products (FCOVER and LAI) and the EVI estimate not corrected for BRDF, all indicate a peak in October. It is noted, however, that there are differences in magnitude between the MODIS- and VGT-derived LAI estimates. The MODIS-derived LAI mean ranges from 4.39 to 5.99 , while the VGT-derived LAI has a lower range, from 3.67 to 5 . Nevertheless, correlation analysis indicated that the two LAI datasets were highly correlated, with a correlation coefficient of 0.83 .

The effect of the BRDF correction can also be noted by comparing the monthly variation between the BRDFuncorrected and the BRDF-corrected EVI data. For instance, the BRDF-uncorrected EVI has an overall range from 0.43 to 0.52 , while the range of the BRDFcorrected EVI is higher, from 0.51 to 0.6. Additionally, the overall form of the mean 'greenness' trends for the indices differ. The variation in the BRDF-uncorrected $\mathrm{EVI}$, for instance, is more or less flat between January 
and July, after which it starts to increase, while the BRDF-corrected EVI has peaks in both April and September, with the latter peak being larger. FCOVER shows a distinct pattern reaching a minimum value in May and a maximum in October. Nevertheless, there is a clear correlation between the two VIs (coefficient of correlation of 0.69 ).

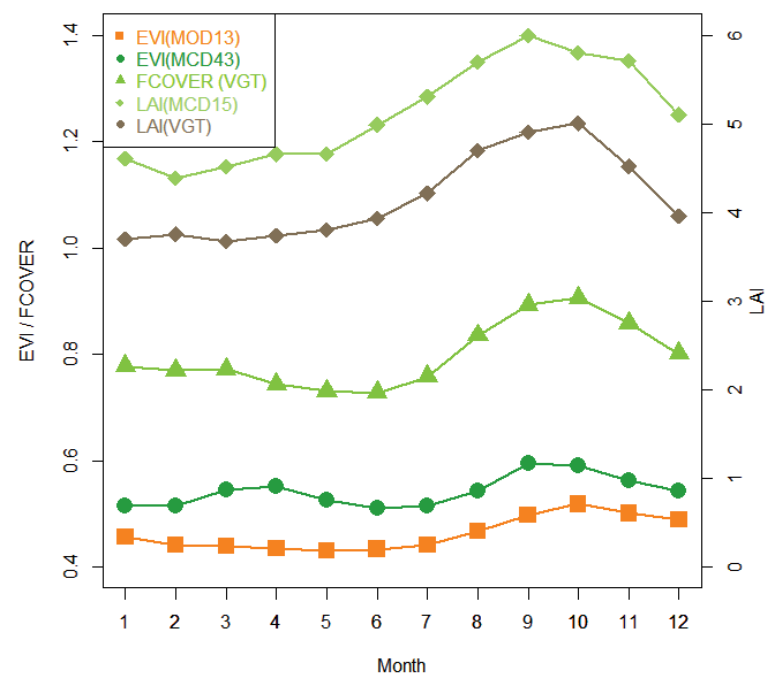

Figure 2: Mean monthly variation in the different VIs, at the scale of French Guiana. Note that, unlike EVI (MCD43) and FCOVER, EVI (MOD13) is not corrected for BRDF effects, while $L A l$ is, by the way it is estimated, insensitive to BRDF effects.

Statistical analysis reveals that there are significant differences between the median FCOVER estimates for the wet season (December to July) and the dry season (August to October) - see Figure 3. (In that figure, the months which share the same letter such as JanuaryJuly are not significantly different.)

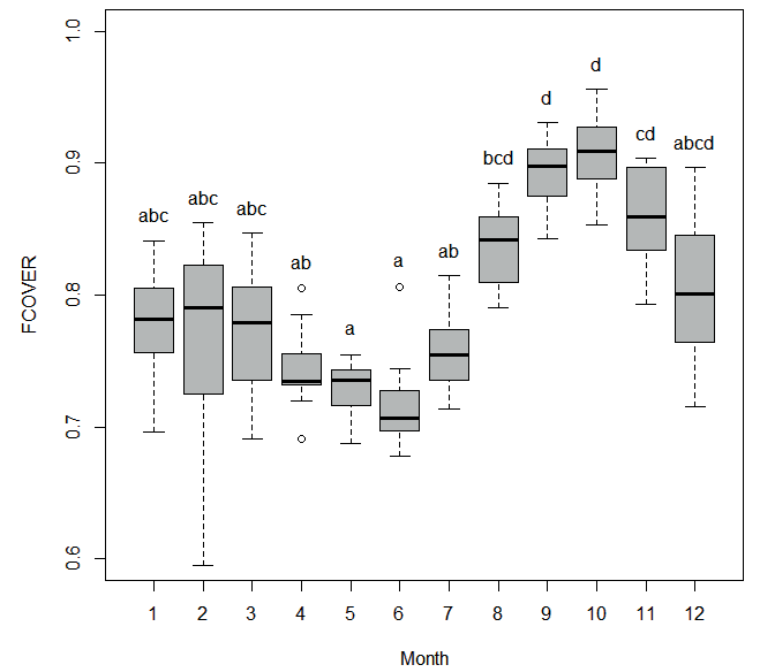

Figure 3: Monthly variation in FCOVER at the scale of French Guiana. Similar letters indicate that the FCOVER values are not significantly different, as the Kruskal-Wallis comparison test was not rejected at the 0.05 significance level.

Overall, the median FCOVER values for the months of September and October are significantly higher than the wet season months (Kruskal-Wallis test; P-value <
0.05). Similar trends are revealed in analyses of the EVI and LAI data, with the EVI data also showing September and October's median values to be significantly different overall from the wet season months. For the LAI data (from both MODIS and VGT), August, September and October have significantly higher values than the wet season months, in general (results not shown).

\section{$3.2 \mathrm{VI}$ variation at the site-level}

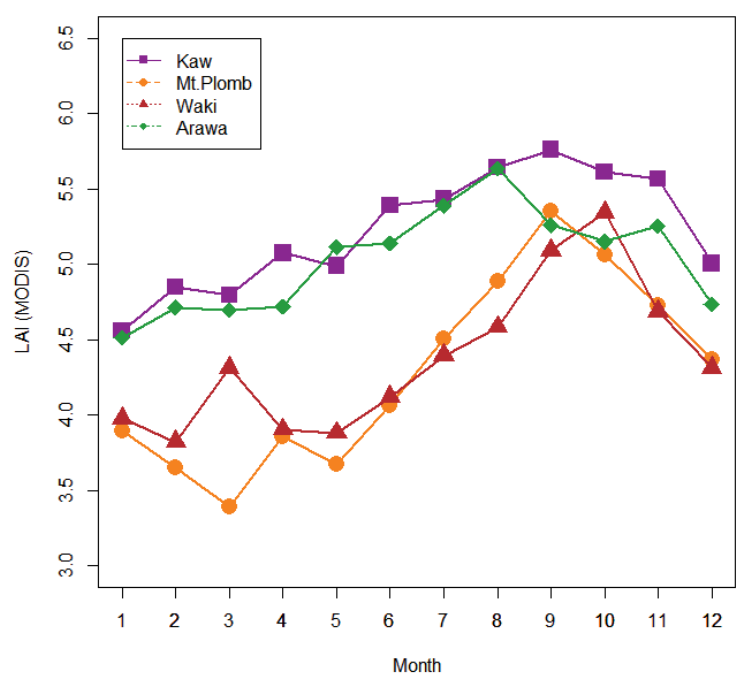

Figure 4: Mean monthly MODIS-derived LAI variation at the 4 sites in French Guiana.

In terms of the site-level analysis, clouds caused large data gaps in the wet season data for EVI, and VGTderived FCOVER and LAI. Hence, the only index for which a full archive for all sites could be generated was the MODIS-derived LAI (Figure 4). While LAI for the 4 sites is shown to display an overall trend similar to that for all of French Guiana, the differences in trends between sites are quite pronounced, and that to (i) magnitude, (ii) greenness peaks, and (iii) overall form of the trend. For instance, in terms of the overall form of the trend, for both Montagne Plomb and Waki, the trend is steeper, suggesting a greater distinction in leaf flushing between the earlier and later parts of the year, compared to the Arawa and Kaw sites. More significantly, the timing of greenness at each of the sites is different. For example, the data indicate that for both Montagne Plomb and Kaw, the peak of greenness is in September, while for Arawa, the peak is a few months earlier, in July, and Waki has its peak greenness in October. While there is some overlap in terms of the magnitude of LAI, overall, the ranges are distinct. For instance, in Montagne Plomb the LAI ranges from 3.39 to 5.35 , while for Waki, LAl ranges from 3.82 to 5.34 . The ranges of LAl for both Arawa and Kaw is overall higher than that of the other two sites, with Arawa's LAI ranging from 4.51 to 5.63 , and Kaw's being the highest overall LAI range, from 4.56 to 5.76 .

Using Kaw as an example, it can also be seen that there is a great deal of month-to-month variance in terms of the LAl estimates (Figure 5). A closer examination of the LAI data indicates that Kaw's peak greenness, mainly occurred in September (e.g. 2003, 2006, 2007, 2008, 2009, 2012, 2013), but in some years $(2002,2004,2005,2010,2011)$, that peak shifted a few months earlier or later. The seasonal trends are 
also confirmed by statistical analysis. In the case of Kaw, for example, the LAl values in the period August to November are significantly higher than in the wet season. In the case of Montagne Plomb, overall, the LAl values for August through October were significantly higher than the wet season months, while for Waki, only September to October had significantly higher LAI. In the case of Arawa, statistical analysis indicated that only during the month of August were LAI values significantly higher than in the wet season months of January and March.

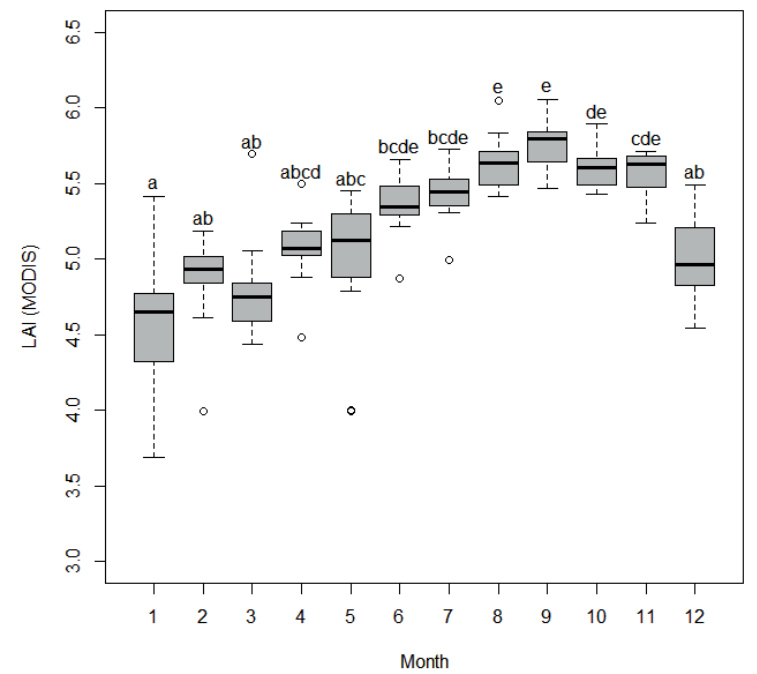

Figure 5: Monthly variation in MODIS-derived LAI at the Kaw site. Similar letters indicate that the $L A l$ values are not significantly different, as the Kruskal-Wallis comparison test was not rejected at 0.05 significance level.

\section{Discussion}

This study has demonstrated that BRDF-corrected vegetation index data for French Guiana's forests demonstrate seasonal patterns. That is to say, at the scale of all of French Guiana, the data does show significant variation between the wet and dry seasons. A range of indices derived from multiple satellite sensors show, for instance, that the VI data for the dry season months of August to October are, in general, significantly higher than for the wet season months. Additionally, such variation is also evident at finer scales. While the results differ somewhat from an earlier study using data not corrected for BRDF, the seasonal pattern does not disappear with the BRDF corrections. The implications of the findings thus warrant further exploration.

\section{Differences in VI estimates}

The VIs used differ in magnitude, and somewhat in the trends shown. It should, however, be recalled that the indices used represent different concepts, and have values with different scaling. For instance, the range of LAI values is typically $0-7$, while both EVI and FCOVER have a maximum value of 1 , representing a $100 \%$ cover rate (Baret \& Weiss 2014). Furthermore, both EVI and FCOVER represent characteristics at the surface of the canopy (Camacho et al. 2009, Huete et al. 1999). LAl, on the other hand, is defined as "the ratio of leaf area to land surface area in a vertical column," essentially an indicator of the quantity of leaf material within a section of forest (Chase et al. 1996). Thus, it would be expected that LAl's estimates of leaf quantity, would be different than the gap fraction estimates of FCOVER, even if it is known that gap fraction influences total leaf area (Camacho et al. 2009, Baret et al. 2013).

It was also noted that while the LAI trends for both the MODIS- and VGT-derived estimates were similar, on average, the VGT-derived LAI estimates were $19 \%$ lower than the MODIS-derived estimates. A study over western Africa came up with similar results when comparing MODIS-derived LAI and VGT-derived LAI, but concluded that two factors likely caused it: (i) very different algorithms used to estimate LAI, and (ii) different product temporal windows, i.e. MODIS' 8-day window compared to the VGT LAI 30-day window (Gessner et al. 2013). Nevertheless, while the VGTderived LAI estimates are overall lower than the MODIS-derived estimates, correlation analysis did indicate that their month-to-month variation is similar.

\section{BRDF corrections}

An important point to emphasize is that data which was (a) corrected for BRDF, (b) generated independently from different satellite sensors, and (c) generated from distinct algorithms, indicate a dry season 'green-up' in French Guiana. This may seem to be contrary to results from recent studies questioning the Amazon green-up findings derived from BRDF-affected VIs (Morton et al. 2014). One commentary even referred to the Amazon green-up findings as a "green illusion" (Soudani \& François 2014). Dry season green-up may even seem counter-intuitive, because as stated in one earlier study, for "Amazon forests... [such green up is] opposite to ecosystem model predictions [indicating] that water limitation should cause dry season declines in forest canopy photosynthesis" (Huete et al. 2006).

Nevertheless, it should be recalled that the recent studies have not said that Amazon green-up is not occurring, but rather that with data not corrected for BRDF, it could not be established (Morton et al. 2014, Soudani \& François 2014). Thus, in the present study, BRDF-corrected data was used to examine the issue of green-up, and even with BRDF-corrected data, strong seasonal patterns are evident. In other words, the seasonal patterns which were detected in the earlier study of Vls over French Guiana's forests were not necessarily BRDF artefacts (Pennec et al. 2011). It also bears repeating that the seasonal patterns were evident across different VIs, as well as across different types of forest in different sites. It should also be noted that the BRDF-related study focused on a different part of the Amazon, and it may well be that patterns there differ from further north, in the Guiana Shield (Saleska et al. 2007, Bradley et al. 2011, Morton et al. 2014). And if there were any doubts regarding the BRDF corrections, it should be recalled that the MCD43 source data was validated in a global study that looked at albedo estimates for a range of sites, including the flux tower in French Guiana (Cescatti et al. 2012).

\section{Field and other evidence of phenological variation}

If it can be accepted that the VIs do indeed demonstrate seasonal phenological variation in French Guiana's forests, it begs the question regarding whether field data support such findings. Previous studies do actually 
support the idea that French Guiana's forests are, to some degree, seasonal (e.g. Sabatier 1985, Sabatier \& Puig 1986, Wagner et al. 2013, Fayad et al. 2014). For instance, one recent study used space-based light detection and ranging (LiDAR) data to show changes in biomass across the wet and dry seasons, in selected plots in the south of French Guiana (Fayad et al. 2014). Another showed a seasonal pattern to litter production in Paracou in northern French Guiana, with peaks between late August and mid-September, which, when compared to field estimates of LAl for the same site, suggests increased leaf production during that time frame (Wagner et al. 2013). The findings of other, earlier studies also point to leaf flushing in the dry season (Sabatier 1985, Sabatier \& Puig 1986).

\section{VI increases signify leaf flushing?}

It has been demonstrated that VI estimates for French Guiana are significantly higher in the dry season than in the wet season. What those findings mean in terms of actual changes on the ground remains unsettled, for lack of concrete field data to confirm the findings from the satellite data. However, in light of the findings of the previous studies looking at phenology, and in light of what is known about VIs, a hypothesis emerges. Overall, the VIs indicate a dry season increase in photosynthetic activity, while the increase in satelliteestimated LAl would point to an increase in the leaf surface, i.e. leaf-flushing. Thus, the likely explanation would be that the dry season 'green-up' observed by the satellites is an increase in leaf flushing.

\section{Patterns vary by forest types}

The second research question of this study sought to determine whether the $\mathrm{VI}$ trends observed at the scale of all of French Guiana 'held' at local scales. The reasoning behind that question was the idea that the overall, French Guiana-wide patterns might merely be due to the spatial averaging of patterns which vary by zones. It has been shown, however, that such is not the case, as the site-level patterns are generally similar to the French Guiana-wide patterns. Nevertheless, it has also been observed that the timing of green-up does vary between sites. The cause for such variation warrants further investigation, as local variations in VIs may be due to local variations in environmental conditions (e.g. differing light availability or soil moisture). Nevertheless, one observation is that the species composition of the 4 sites was known to differ. For instance, the Kaw site was dominated by mangrove species like Avicennia germinans (black mangrove) and Rhizophora mangle (red mangrove), while the Waki site was dominated by Parinari trees (Parinari campestris). A simple hypothesis is that the phenology (represented by the VIs) varies by species composition.

\section{Future research}

The findings presented here ultimately warrant validation in the field to test some of the hypotheses proposed (e.g. that the dry season increase in VIs is caused by real leaf flushing). The factors driving the observed patterns should also be considered. For instance, some studies explored how hydrology (soil water availability) influences the distribution of tree species in French Guiana (e.g. Pélissier et al 2002). One idea is that perhaps the timing of the greening of
French Guiana's forests is linked to soil water availability, which could carry a lag with rainfall. One recent study suggested that in some parts of the greater Amazon Basin, there is a lag between rainfall and vegetation response, and that lag could be due to the underlying hydrology (Bradley et al. 2011). While it was not explicitly addressed in this study, the pattern in the vegetation indices seems to align with the climate seasonality in the form of the amount of available radiation. That also merits further research.

\section{Conclusions}

This study has demonstrated how the 'big data' collected by environmental monitoring satellites can potentially be exploited to monitor the phenological variation of remote and inaccessible tropical forests. While some discrepancies were noted in terms of how indices from different sensors observe vegetation (e.g. in the case of LAl estimates), overall, the green-up trends for French Guiana from different indices and different sensors was similar. The data suggest annually recurring leaf-flushing in the SeptemberOctober timeframe. Compared to a similar, earlier study which had used vegetation index data not corrected for BRDF effects, this study reasserts that French Guiana's forests do indeed display seasonality (Pennec et al. 2011). This was observed at the scale of all of French Guiana, as well as smaller study sites.

\section{Acknowledgements}

This research is supported through the Forest \& Nature for Society (FONASO) joint doctoral programme of the European Union's Erasmus Mundus initiative (Specific Grant Agreement 2013-1462/001-001-EMIIE-MJD). This research was also conducted in the context of the BGF-funded DynForDiv project (2014-2017). The contributions of IRD, UMR AMAP, AgroParisTech, and TU Dresden are also greatly appreciated. This paper also benefited from the feedback of two anonymous reviewers.

\section{References}

Baret F., Weiss M., Lacaze R., Camacho F., Makhmara H., Pacholcyzk O., Smets B. 2013. GEOV1: LAl and FPAR essential climate variables and FCOVER global time series capitalizing over existing products. Part1: Principles of development and production. Remote Sensing of Environment, 137: 299-309.

Baret F., Weiss, M. 2014. Algorithm Theoretical Basis Document: Leaf Area Index (LAl) - Version 1. Technical document. Document No. GIOGL1_ATBD GEOV1. European Commission / GIO-GL consortium. 51 pp.

Bi J., Choi S., Park T., Kntazikhin Y., Myneni, R. 2014. Seasonality of Amazon Forests Not a Sun-Sensor Illusion. Presentation. MODIS Science Team Meeting, April 29 - May 1, 2014. Columbia, Maryland.

Bradley A.V., Gerard F.F., Barbier N., Weedon G.P., Anderson L.O., Huntingford C., Aragaõ L.E.O.C., Zelazowski P., Arai E., 2011. Relationships between phenology, radiation and precipitation in the Amazon region. Global Change Biology, 17: 2245-2260. 
Camacho F., Lacaze R., Smets B. 2009. BioPar Product User Manual: Fraction of Green Vegetation Cover (FCover) version 0 from SPOT / VEGETATION data. Technical document. Document no. g2-BP-RPBP053. European Commission / Geoland2 consortium. $28 \mathrm{pp}$.

Cescatti A., Marcolla B., Santhana Vannan S.K., Pan J.Y., Roman M.O., Yang X., Ciais P., Cook R.B., Law B.E., Matteucci G., Migliavacca M., Moors E., Richardson A.D., Seufert G., Schaaf C.B. 2012. Intercomparison of MODIS albedo retrievals and in situ measurements across the global FLUXNET network. Remote Sensing of Environment, 121: 323-334.

Chase T.N., Pielke R.A., Kittel T.G.F., Nemani R., Running S.W. 1996. Sensitivity of a general circulation model to global changes in leaf area index. Journal of Geophysical Research, 10: 7393-7408.

Fayad I., Baghdadi N., Gond V., Bailly J.S., Barbier N., El Hajj M., Fabre F. 2014. Coupling potential of ICESat/GLAS and SRTM for the discrimination of forest landscape types in French Guiana. International Journal of Applied Earth Observation and Geoinformation, 33: 21-31.

Gessner U., Niklaus M., Kuenzer C., Dech S. 2013. Intercomparison of Leaf Area Index Products for a Gradient of Sub-Humid to Arid Environments in West Africa. Remote Sensing, 5: 1235-1257.

Gond V., Fayolle A., Pennec A., Cornu G., Mayaux P., Camberlin P., Doumenge C., Fauvet N., Gourlet-Fleury S. 2013. Vegetation structure and greenness in Central Africa from MODIS multi-temporal data. Philosophical Transactions of the Royal Society B, 368: 20120309.

Hansen M.C., DeFries R.S., Townshend J.R.G., Carroll M., Dimiceli C., Sohlberg R.A. 2003. Global Percent Tree Cover at a Spatial Resolution of 500 Meters: First Results of the MODIS Vegetation Continuous Fields Algorithm. Earth Interactions, 7: 1-15.

Hansen M.C., Potapov P.V., Moore, R., Hancher M., Turubanova S.A., Tyukavina A., Thau D., Stehman S.V., Goetz S.J., Loveland T.R., Kommareddy A., Egorov A., Chini L., Justice C.O., Townshend J.R.G. 2013. High-Resolution Global Maps of 21st-Century Forest Cover Change. Science 15 (342): 850-853.

Huete A., Justice C., van Leeuwen W. 1999. MODIS Vegetation Index (MOD13): Algorithm Theoretical Basis Document. Technical document. NASA / University of Arizona.

129

pp.

Huete A.R., Didan K., Shimabukuro Y.E., Ratana P., Saleska S.R., Hutrya L.R., Yang W., Nemani R.R. 2006. Amazon rainforests green-up with sunlight in dry season. Geophysical Research Letters, 33: L06405.

Jensen, J.R. 2006. Remote Sensing of the Environment: An Earth Resource Perspective. Second Edition. Prentice Hall. 608 pp.

Lillesand T.M., Kiefer R.W., Chipman J.W. 2007. Remote Sensing \& Image Interpretation. Sixth Edition. Wiley \& Sons. 756 pp.
Morton D.C., Nagol J., Carabajal C.C., Rosette J., Palace M., Cook B.D., Vermote E.F., Harding D.J., North P.R.J. 2014. Amazon forests maintain consistent canopy structure and greenness during the dry season. Nature, 506: 221-224.

Myneni R.B., Keeling C.D., Tucker C.J., Asrar G., Nemani R.R. 1997. Increased plant growth in the northern high latitudes from 1981 to 1991. Nature, 386: 698-702.

Nagol J.R., Sexton J.O., Kim D., Anand A., Morton D., Vermote E., Townshend J.R. 2015. Bidirectional effects in Landsat reflectance estimates: Is there a problem to solve? ISPRS Journal of Photogrammetry and Remote Sensing, 103: 129-135.

Pélissier R., Dray S., Sabatier D. 2002. Within-plot relationships between tree species occurrences and hydrological soil constraints: an example in French Guiana investigated through canonical correlation analysis. Plant Ecology, 162: 143-156.

Pennec A., Gond V., Sabatier D., 2011. Characterization of tropical forests phenology in French Guiana using MODIS time-series. Remote Sensing Letters, 2: 337-345.

Pohlert T. 2014. The Pairwise Multiple Comparison of Mean Ranks Package (PMCMR). R package. http://CRAN.R-project.org/package=PMCMR.

Sabatier, D. 1985. Saisonnalité et déterminisme du pic de fructification en forêt Guyanaise. Rev. Ecol. (Terre Vic), 40: 289-320.

Sabatier D., Puig H. 1986. Phénologie et saisonnalité de la floraison et de la fructification en forêt dense guyanaise. In Vertèbres et forêts tropicales humides d'Afrique et d'Amérique: 173-184.

Saleska S.R., Disan K., Huete A.R., de Rocha H.R. 2007. Amazon Forests Green Up During 2005 Drought. Science, 318: 612.

Schaaf C.B., Strahler A.H., Gao F., Jin Y. 2002. MODIS BRDF/Albedo Product: Evaluation, Validation, and Applications. Presentation. MODIS Science Team Meeting, July 22-24, 2002. Greenbelt, Maryland.

Soudani K., François, C. 2014. A green illusion. Nature, 506: $165-166$

Tucker, C.J. 1979. Red and Photographic Infrared Linear Combinations for Monitoring Vegetation. Remote Sensing of Environment, 8: 127-150.

Viennois, G., Barbier, N., Fabre, I., Couteron, P. 2013. Multiresolution quantification of deciduousness in West Central African forests. Biogeosciences, 10: 6957-6967.

Wagner F., Rossi V., Stahl C., Bonal D., Herault B. 2013. Asynchronism in leaf and wood production in tropical forests: a study combining satellite and groundbased measurements. Biogeosciences, 10: 7307-7321. 